\title{
PENDAMPINGAN IBU HAMIL TENTANG PENYULIT MATERNAL TERHADAP PENGETAHUAN DAN SIKAP IBU HAMIL DI TANGERANG
}

\author{
Erna Mesra \\ Jurusan Keperawatan Poltekkes Kemenkes Banten \\ Korespondensi : ernamesra@gmail.com
}

\begin{abstract}
ABSTRAK
Pengawasan Antenatal merupakan cara untuk mendukung kesehatan ibu hamil, untuk deteksi dini penyulit maternal. Peran perawat pada saat pelayanan antenatal adalah melakukan promosi kesehatan tentang penyulit maternal, dengan adanya promosi kesehatan diharapkan akan mempengaruhi masyarakat, individu maupun kelompok berperilaku hidup sehat, dengan memanfaatkan fasilitas kesehatan. Masa kehamilan merupakan salah satu masa penentu baik untuk kesejahteraan ibu dan janin, berkaitan dengan kedaruratan yang mungkin dialami ibu saat kehamilan muda atau kehamilan lanjut yang menimbulkan kegawadarutan pada ibu an janin. Semua penyulit kehamilan atau komplikasi yang terjadi dapat dihindari bila kehamilan direncanakan dikelola secara benar.Jenis penelitian adalah penelitian eksperimen kuasi (Quasi experiment) dengan rancangan penelitian Two Group Pretest Posttest. Hasil Ada Perbedaan signifikan pengetahuan sebelum dan sesudah pendampingan pada kelompok intervensi didapatkan mean 13.06 dan $t$ test 56.25 dan $p$ value 0.000 . Perbedaan pengetahuan pre dan post pada kelompok intervensi secara signifikan sebelum dan sesudah pendampingan mean 18.69 dan $t$ test 48.187, $p$ value 0,000 ada perbedaan signifikan pengetahuan pada kelompok intervensi. Kesimpulan ada perubahan pengetahuan dan sikap antara kelompok perlakuan yang dilakukan pendampingan dengan kelompok kontrol yang tidak dilakukan pendampingan pendidikan kesehatan. Saran setiap ibu hamil diberi penyuluhan tentang penyulit maternal dan melakukan deteksi dini tanda bahaya kehamilan
\end{abstract}

\section{Kata Kunci : Penyulit Maternal Bidan Praktek Mandiri}

\section{PENDAHULUAN}

AKI di Indonesia 359 per 100.000 kelahiran hidup dan AKB di Indonesia 32 per 1.000 kelahiran hidup. Lima penyebab kematian ibu terbesar yaitu perdarahan, Hipertensi Dalam Kehamilan (HDK), infeksi, partus lama/macet, dan abortus (Kementerian Kesehatan RI 2015). Upaya percepatan penurunan AKI adalah pelayanan antenatal dan pengawasan antenatal merupakan cara mendukung kesehatan ibu hamil, untuk mendeteksi secara dini penyulit maternal. Peran perawat

Jurnal Medikes, Volume 5, Edisi 2, November 2018 
pada pelayanan antenatal adalah melakukan promosi kesehatan tentang penyulit maternal, dengan promosi kesehatan diharapkan mempengaruhi masyarakat, baik individu maupun kelompok untuk berperilaku hidup sehat, dengan memanfaatkan fasilitas kesehatan. Pencegahan kematian ibu dengan melaksanakan pemeriksaan antenatal secara teratur sesuai pedoman pemeriksaan kehamilan minimal empat kali secara teratur. Pemeriksaan antenatal, ibu mendapatkan pengetahuan dan pendidikan tentang penyulit maternal pada ibu hamil. Masa kehamilan merupakan masa penentu untuk kesejahteraan ibu dan janin. Penyulit maternal yang dialami ibu saat hamil muda atau kehamilan lanjut berdampak menimbulkan kegawadarutan pada janin, ibu atau keduaduanya. Kedaruratan pada hamil muda adalah abortus dapat mengancam janin maupun ibu, pada kehamilan lanjut penyebab tingginya angka kematian ibu adalah pre eklamsi dan eklamsia. Kemampuan kinerja petugas kesehatan berdampak langsung pada peningkatan kualitas pelayanan kesehatan maternal terutama kemampuan dalam mengatasi masalah kehamilan dan kegawatdaruratan. Penyulit kehamilan atau komplikasi yang terjadi dapat dihindari apabila kehamilan direncanakan dikelola secara benar dan memberikan asuhan kehamilan yang cepat, tepat dan benar diperlukan tenaga kesehatan yang terampil dan professional dalam menurunkan AKI dan AKB.

Penyebab tidak langsung kematian ibu adalah karena kondisi masyarakat seperti pendidikan, sosial ekonomi dan budaya, kondisi geografi serta keadaan sarana pelayanan yang kurang siap ikut memperberat permasalahan ini. Beberapa hal tersebut mengakibatkan kondisi 3 terlambat (terlambat mengambil keputusan, terlambat sampai di tempat pelayanan dan terlambat mendapatkan pertolongan yang adekuat) dan 4 terlalu (terlalu tua, terlalu muda, terlalu banyak, terlalu rapat jarak kelahiran). Kehamilan pada seorang perempuan merupakan suatu hal yang terjadi secara alamiah sebagai upaya untuk penerus garis keturunan yang sangat diharapkan dalam keluarga. Dalam perkembangan selama +9 bulan membutuhkan pengawasan baik dalam kehamilan muda, demikian pula saat janin berkembang pada usia kehamilan selanjutnya, dibutuhkan tenaga kesehatan yang kompeten untuk bisa mengatasi kegawatdaruratan maternal neonatal untuk menyelamatkan bangsa dengan memberdayakan ibu hamil dengan pendampingan untuk meningkatkan pengetahuan ibu hamil.

Tujuan penelitian adalah untuk mengetahui pengaruh pendampingan ibu hamil 
primigravida tentang penyulit maternal terhadap pengetahuan ibu hamil trimester I di Bidan Praktek Mandiri Tangerang.

\section{METODE}

Jenis penelitian adalah penelitian eksperimen kuasi (Quasi experiment) dengan rancangan penelitian Two Group Pretest Posttest. Penelitian ini melakukan pre dan pos test pada kelompok eksperimen maupun kelompok kontrol pada waktu yang bersamaan, dimana hanya kelompok eksperimen saja yang mendapat perlakuan. Pretest Intervensi Postest Teknik sampling yang digunakan pada penelitian ini menggunakan non probability sampling dengan pendekatan purposive sampling, didasarkan pada suatu pertimbangan tertentu yang dibuat oleh peneliti sendiri,berdasakan ciri atau sifat-sifat populasi yang sudah diketahui sebelumnya Pada penelitian ini dibagi menjadi 2 (dua) kelompokyaitu kelompok intervensi dan kelompok kontrol, yang masing-masing kelompok ada 36 responden, jadi total sampelnya ada 72 responden.Pengambilan sampel berdasarkan kriteria inklusi dan eksklusi. Data dalam penelitian ini adalah data primer. Data primer diambil secara langsung kepada responden dengan menggunakan instrument berupa kuesioner dan daftar tilik.
Analisa dengan analisa univariat dan Analisis Bivariat Menggunakan uji dependen $t$ tes

\section{HASIL}

Penelitian ini dilakukan di Bidan Praktek mandiri Tangerang Tentang model pendampingan ibu hamil primigravida tentang penyulit maternal terhadap pengetahuan dan sikap ibu hamil trimester I di bidan praktek mandiri Tangerang Tahun 2018. Metode penelitian Penelitian ini menggunakan metode penelitian eksperimen semu (quasi eksperimen). Selama kehamilan Trimester I, ibu diberikan penyuluhan kesehatan tentang Tentang penyulit maternal pada ibu hamil dan diberi buku saku, setelah satu bulan dilakukan penilaian dengan menggunakan kuesioner

\section{Tabel 1}

Distribusi Frekuensi Responden berdasarkan Karakteristik di BPM Tangerang tahun 2018

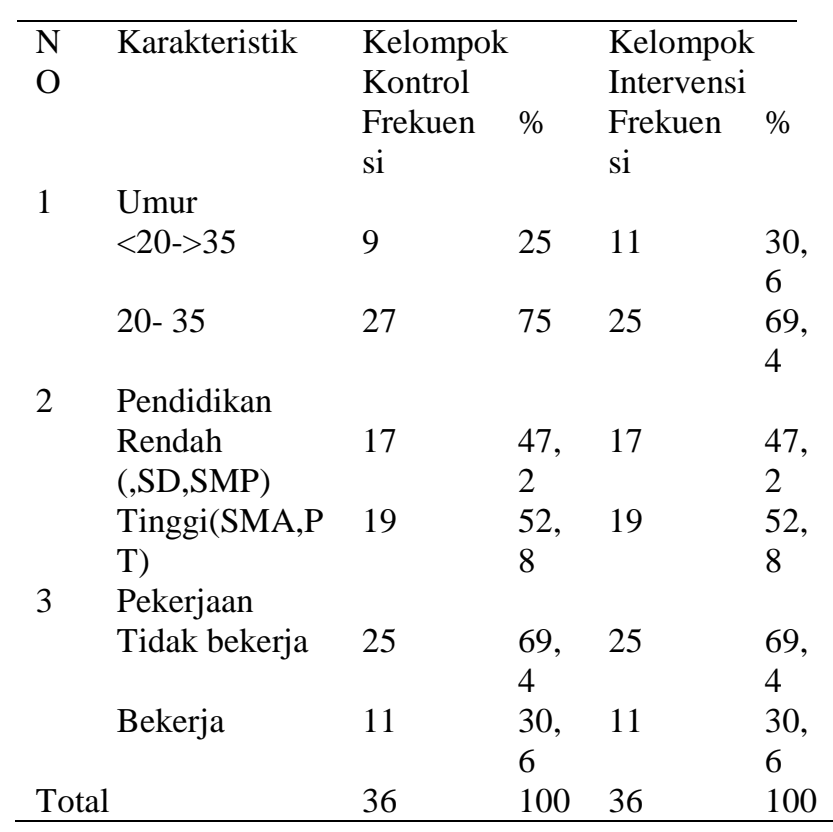


Tabel $125 \%$ umur beresiko pada kelompok kontrol , pada kelompok perlakuan ditunjukkan bahwa 30,6 \% responden umur beresiko Pendidikan responden 52,8\% SMA dan 47,2 \% bependidikan SMP pada kelompok kontrol , kelompok perlakuan 52,8 $\%$ responden pendidikan SMA dan $42,7 \%$ pendidikan SMP. Pekerjaan 69,4 \% responden tidak bekerja hanya 30,6\% yang bekerja pada kelompok kontrol, Pada kelompok perlakuan 69,4\% tidak bekerja dan 30,6\% bekerja pada kelompok Perlakuan

Tabel 2

T-Test (pada masing - masing kelompok pengetahuan )

\begin{tabular}{|c|c|c|c|c|c|c|c|}
\hline \multirow{4}{*}{$\begin{array}{c}\text { Varia } \\
\text { bel }\end{array}$} & \multirow{4}{*}{$\begin{array}{c}\text { Mea } \\
\mathrm{n}\end{array}$} & \multirow{4}{*}{$\begin{array}{c}\text { Std } \\
\text { Devi } \\
\text { asi }\end{array}$} & \multicolumn{2}{|c|}{$95 \%$} & \multirow[t]{5}{*}{$t$} & \multirow{5}{*}{$\begin{array}{l}\text { d } \\
\text { f }\end{array}$} & \multirow{5}{*}{$\begin{array}{c}\text { Sig } \\
\cdot \\
(2- \\
\text { tail } \\
\text { ed) }\end{array}$} \\
\hline & & & \multicolumn{2}{|c|}{$\begin{array}{c}\text { Confidence } \\
\text { Interval }\end{array}$} & & & \\
\hline & & & Lo & Upp & & & \\
\hline & & & we & er & & & \\
\hline & & & $\mathrm{r}$ & & & & \\
\hline \multicolumn{8}{|l|}{ Kontr } \\
\hline ol & 5.44 & 1.66 & 6.00 & 4.88 & 19.6 & 3 & 0,00 \\
\hline $\begin{array}{c}\text { Pre- } \\
\text { postes }\end{array}$ & 4 & 4 & 7 & 1 & 34 & 5 & 0 \\
\hline \multicolumn{8}{|l|}{ Interv } \\
\hline ensi & 13,0 & 1,39 & 13.5 & 12.5 & 56.2 & 3 & 0,00 \\
\hline $\begin{array}{c}\text { Pre- } \\
\text { postes }\end{array}$ & 56 & 3 & 27 & 84 & 45 & 5 & 0 \\
\hline
\end{tabular}

Tabel 2 Pengetahuan pre-test dan pos-test Menunjukkan nilai $t$-test $=19.634$ dan nilai $p$ value 0,000 keputusan ada perbedaan signifikan. Pengetahuan pre-test dan pos-test nilai $t$ - test 56.245 dan nilai $p$ value 0,000 kesimpulan ada perubahan pengetahuan

Jurnal Medikes, Volume 5, Edisi 2, November 2018 antara kelompok perlakuan dengan kelompok kontrol.

Tabel 3

T-Test (pada masing - masing kelompok sikap )

\begin{tabular}{|c|c|c|c|c|c|c|c|}
\hline \multicolumn{8}{|c|}{ sikap ) } \\
\hline \multirow{3}{*}{$\begin{array}{c}\text { Variab } \\
\text { el }\end{array}$} & \multirow{3}{*}{$\begin{array}{c}\text { Mea } \\
\mathrm{n}\end{array}$} & \multirow{3}{*}{$\begin{array}{l}\text { Std } \\
\text { Devi } \\
\text { asi }\end{array}$} & \multirow{2}{*}{\multicolumn{2}{|c|}{$\begin{array}{c}95 \% \\
\text { Confidence } \\
\text { Interval }\end{array}$}} & \multirow[t]{3}{*}{$\mathrm{t}$} & \multirow{3}{*}{$\begin{array}{l}\mathrm{d} \\
\mathrm{f}\end{array}$} & Sig. \\
\hline & & & & & & & $\begin{array}{l}(2- \\
\text { taile }\end{array}$ \\
\hline & & & $\begin{array}{c}\text { Low } \\
\text { er }\end{array}$ & $\begin{array}{c}\text { Upp } \\
\text { er }\end{array}$ & & & d) \\
\hline Kontr & & & & 4.77 & & & \\
\hline ol & 5.71 & 2,75 & 6.65 & 0 & 12.2 & 3 & 0,00 \\
\hline $\begin{array}{c}\text { Pre- } \\
\text { postes }\end{array}$ & 4 & 0 & 9 & & 93 & 5 & 0 \\
\hline $\begin{array}{c}\text { Interv } \\
\text { ensi }\end{array}$ & 11.6 & 1.75 & 12.2 & 11.1 & 40.0 & 3 & 0,00 \\
\hline $\begin{array}{c}\text { Pre- } \\
\text { postes }\end{array}$ & 94 & 4 & 88 & 01 & 11 & 5 & 0 \\
\hline
\end{tabular}

Tabel 3 Sikap pre-test dan pos-test pada kelompok kontrol Menunjukkan nilai $t$-test $=$ 12.293 dan nilai $p$ value 0,000 keputusan ada perbedaan signifikan. Sikap pre-test dan postest kelompok intervensi nilai t- test 40.011 dan nilai $p$ value 0,000 kesimpulan ada perubahan sikap antara kelompok perlakuan dengan kelompok kontrol.

\section{PEMBAHASAN}

\section{Umur}

Umur antara 21-35 tahun dalam masa reproduktif sehat dan resiko rendah untuk hamil dan melahirkan sesuai teori Manuaba 2015 reproduksi sehat, umur aman untuk kehamilan dan persalinan adalah usia 21-35 tahun, dan usia diatas 35 tahun dan dibawah 20 tahun menjadi umur 
yang rawan untuk kehamilan dan persalinan . Penelitian Sukesih (2012) ibu umur 20-35 tahun berpeluang 7.3 kali dapat menerima pengetahuan. Notoadmojo (2007) usia berpengaruh terhadap daya tangkap dan pola pikir seseorang Umur mempunyai pengaruh terhadap pengetahuan dan pengalaman yang dapat mempengaruhi pola pikir terhadap suatu objek dan informasi yang diberikan. Umur dalam hubungannya dengan pengetahuan berperan sebagai faktor intrinsik. Umur berhubungan dengan dengan struktur organ reproduksi dan fungsi faal, termasuk system hormonal seorang perempuan.

\section{Pendidikan}

Pendidikan sangat penting dalam mempengaruhi prilaku seseorang dalam pengambilan keputusan. Notoatmodjo (2007), pendidikan merupakan suatu proses dengan sendirinya memiliki masukan dan keluaran. Menurut peneliti tingkat pendidikan mempunyai pengaruh terhadap pengetahuan .Sulistiawati (2009) ibu hamil dengan tingkat pendidikan yang rendah tidak mendapatkan cukup informasi maka ia tidak tahu cara melakukan perawatan kehamilan dengan baik, sesuai penelitian sukesih (2012) ibu hamil dengan pendidikan tinggi berpeluang 8.1 kali lebih baik menangani tanda bahaya kehamilan disbanding pendidikan rendah. Makin tinggi pendidikan seseorang makin mudah menerima informasi, tingkat pendidikan akan sangat mempengaruhi tingkat pengetahuan seseorang karena pendidikan merupakan upaya untuk memberikan pengetahuan sehingga terjadi perubahan perilaku untuk mengetahui tentang penyulit maternal Semakin tinggi tingkat pendidikan ibu diharapkan tinggi pula tingkat pengetahuannya

\section{Pekerjaan}

Pekerjaan adalah kegiatan yang harus dilakukan terutama untuk menunjang kehidupan dan keluarganya. Bekerja bukan alasan untuk seorang ibu untuk hamil, dengan pengetahuan yang benar tentang penyulit maternal dan dukungan lingkungan kerja, penelitian Sukesih (2012) dengan $\mathrm{p}$ value $=0,547(\mathrm{p}>0,05)$ tidak ada hubungan yang bermakna antara pekerjaan dengan seorang ibu yang bekerja terhadap kehamilan. Saat ini terjadi peningkatan jumlah angkatan kerja perempuan di berbagai sektor pekerjaan, penelitian lestari (2012) bahwa ibu hamil yang bekerja $50 \%$ nilai p value $=0,208$ maka tidak ada hubungan yang bermakna antara pekerjaan ibu dengan kehamilan. 


\section{Pengetahuan}

Pengetahuan pre-test dan pos-test nilai $t$ test $=19.634$ dan nilai $p$ value 0,000 keputusan ada perbedaan signifikan. Kelompok Intervensi pre-test dan postest nilai $t$ - test 56.245 dan nilai $p$ value 0,000 kesimpulan ada perubahan pengetahuan antara kelompok perlakuan dengan kelompok kontrol dengan perbedaan nilai t-test 36.611. Penelitian Ripca (2014) nilai t-tes 16,371 dan nilai $\mathrm{p}$ value 0,000. Notoatmojo (2007), pengetahuan adalah hasil tahu dan ini terjadi setelah orang tua melakukan penginderaan terhadap suatu objek tertentu. Pendampingan pada ibu hamil memberikan pengaruh dan dampak meningkatkan pengetahuan, pengalaman dan informasi tentang penyulit maternal, mereka sudah pernah mendapat kuesioner pre test, saat mengerjakan post test memberikan jawaban yang berbeda. Pengetahuan diperoleh dari pendidikan formal namun dapat diperoleh melalui belajar sendiri. Pendidikan sering terjadi dibawah bimbingan orang lain dan secara otodidak

5. Sikap

Sikap pre-test dan pos-test pada kelompok kontrol nilai $t$-test $=12.293$ dan nilai $p$ value 0,000 keputusan ada perbedaan signifikan. Sikap pre-test dan pos-test kelompok intervensi nilai t- test 40.011 dan nilai $p$ value 0,000 ada perubahan sikap antara kelompok perlakuan yang dilakukan pendampingan Penelitian Ode (2015) penyuluhan pemanfaatan buku KIA berpengaruh terhadap sikap deteksi dini tanda bahaya kehamilan dengan $\mathrm{p}$ value 0,000 . Notoatmojo (2010) pendidikan kesehatan dengan menggunakan alat bantu media untuk menyampaikan informasi kesehatan ,alat bantu atau sarana yang digunakan dan dipahami oleh tenaga kesehatan maupun responden untuk memudahkan pemahaman. Penelitian ini didapatan ada perubahan sikap antara kelompok perlakuan yang dilakukan pendampingan dan pendidikan kesehatan tentang penyulit maternal dengan kelompok control. Pendampingan sangat berpengaruh dengan sikap responden, semakin banyak informasi yang diberikan dan obyek yang diketahui maka semakin baik sikap seseorang dalam memahami pengetahuan.

\section{SIMPULAN}

1. Distribusi frekuensi karakteristik 72,2 \% responden umur 20-35 dan pendidikan responden 52,7\% adalah SMA. Pekerjaan 69,4\% responden tidak bekerja. 
2. Perbedaan pengetahuan sebelum dan sesudah pendampingan pada kelompok intervensi mean 13,06 nilai t-test $=56,25$ dan nilai $\mathrm{p}$ value 0,000 . kelompok kontrol mean 5,44 dan nilai $\mathrm{t}$ test $=19,63$ keputusan ada perbedaan signifikan.

3. Perbedaan sikap sebelum dan sesudah pendampingan pada kelompok intervensi mean 11,69 nilai $\mathrm{t}$-test $=40,01$ nilai $\mathrm{p}$ value 0,000 kelompok kontrol mean 5,71 dan nilai $\mathrm{t}$ test $=12,29$ keputusan ada perbedaan signifikan.

\section{DAFTAR PUSTAKA}

Ambarwati, 2010. Asuhan Kebidanan ibu Hamil. Yogyakarta: Mitra Cendikia

Andrews, Gilly, 2010. Buku Ajar Kesehatan Reproduksi Wanita (Woman's Sexual Health) Edisi 2. Jakarta: Buku Kedokteran EGC.

Arikunto, 2006. Prosedur Penelitian Suatu Pendekatan Praktik, Jakarta: Rineka Cipta.

Bagian Obstetrik \& Ginekologi FK UNPAD, Obstetri Patologi, Elstar Offset Bandung Cunningham, 2010. William Obstetri. Ed 21. Jakarta: EGC.
Maternal dan Neonatal. Yayasan Bina Pustaka Sarwono Prawirohadjo. Jakarta.

Manuaba, I.B.G, 2008. Ilmu Kebidanan, Penyakit Kandungan dan Keluarga Berencana. EGC. Jakarta.

Notoatmodjo, S. 2010. Metodologi Penelitian Kesehatan. Jakarta : Rineka Cipta.

Notoatmodjo. Soekidjo. 2010. Promosi Kesehatan dan Ilmu Perilaku. Jakarta : Rineka Cipta.

Pusdiknakes, 2008. Asuhan Kebidanan ibu Hamil . Jakarta: Pusdiknakes

Prawirohadjo, S, 2014. Ilmu kebidanan : Jakarta : Yayasan Bina Pustaka Sarwono.

Saifuddin, Abdul Bari dkk, 2014. Buku Acuan Nasional Pelayanan Kesehatan. EGC

Saleha, 2009. Asuhan Kebidanan Pada Masa Nifas. Jakarta: Salemba Medika.

Varney, 2004. Varney’s Midwifery. Ed 4. Massa chusets: Jones and Bartlett Publisher. 
Varney, Helen, dkk. 2008. Buku Ajar Asuhan

Kebidanan Volume 2 edisi 4. Jakarta : EGC. 